\title{
DESIGN PARA DEFICIENTES VISUAIS: COZINHAR SOB UMA PERSPECTIVA INCLUSIVA
}

Iris Marcela López Rico

Universidad Nacional Autónoma de México

arq.irislopez@hotmail.com

Denise Dantas

Universidade de São Paulo

dedantas@usp.br

Gloria Angélica Martínez de la Peña.

Universidad Nacional Autónoma de México

gmartinez@correo.cua.uam.mx

Resumo: Este artigo mostra a análise decorrente de um estudo qualitativo no qual quatro pessoas com deficiência visual no México e um no Brasil foram entrevistadas e filmadas enquanto cozinhavam em seus próprios locais de trabalho ou moradia. O objetivo da pesquisa foi determinar parâmetros de projeto com foco inclusivo para o espaço e para os utensílios comumente utilizados na cozinha para que a atividade de cozinhar possa ser exercida por deficientes visuais com mais segurança. Após entrevista e filmagem dos usuários, os dados foram analisados comparativamente, destacando aspectos da organização espacial da cozinha, as atividades executadas e os utensílios utilizados. Os resultados apontaram para questões comparativas entre as duas realidades, de modo a estabelecer se aspectos culturais influenciam na atividade de cozinhar para os deficientes dos dois países, além de mostrar aspectos convergentes e divergentes nas duas realidades observadas.

Palavras-chave: design inclusivo, pesquisa qualitativa, cozinhar, deficientes visuais.

Abstract: This article shows the analysis of a qualitative study in which four people with visual disability in Mexico and one in Brazil were interviewed and filmed while cooked in their own workplaces. The goal of the research is to determine the design parameters with inclusive focus on space and objects commonly used in the kitchen for cooking activity may be exercised by the visually impaired. After the interview and footage of people in their places of cooking activities, data were analyzed comparatively, highlighting aspects of the spatial organization of the kitchen, the activities performed, the utensils used. The results point to comparative issues between the two realities, in order to establish cultural aspects influence the cooking activity for disabled people of the two countries, in addition to showing convergent and divergent aspects in two realities observed. 
Keywords: inclusive design, qualitative research, cooking, blind people.

\section{INTRODUÇÃO: LIGANDO OS OBJETOS DE ESTUDO - COZINHAR, DEFICIENTES VISUAIS, DESIGN}

A importância de um estudo focando a atividade de cozinhar reside no fato de esta ser uma das necessidades básicas de todo ser humano. Por outro lado, a cozinha torna-se uma experiência para quem a vive, onde a variação nas formas de execução depende de fatores que vão desde as condições humanas aos aspectos econômicos e culturais em um determinado contexto. No mesmo sentido, gostos pessoais pela cozinha e transformação de produtos alimentares manifestam-se na capacidade e habilidade da pessoa para realizar a atividade.

Por causa de situações como, por exemplo, ter que alimentar outras pessoas e ter que se alimentar, além do prazer inegável que a arte culinária ${ }^{1}$ proporciona, cozinhar torna-se parte fundamental na vida diária de um grande número de pessoas, incluindo aquelas que não têm o sentido da visão. Para estas últimas, a partir de uma série de adaptações e técnicas próprias desenvolvidas através de sua experiência como deficientes visuais, faz-se importante uma constante memorização e estado de atenção e alerta, o que é possível a partir de seus outros sentidos, permitindo-lhes um domínio espacial, bem como a manipulação de objetos e utensílios para a execução dos procedimentos necessários no ato de cozinhar. Por outro lado, há deficientes visuais que consideram cozinhar uma atividade complexa e arriscada que só pode ser realizada por uma pessoa com visão normal, visto que é necessária uma constante atenção visual.

O design é uma atividade criativa que tem como objetivo dar qualidades multifacetadas aos objetos e ao espaço que os contém. Entretanto, estas qualidades também deveriam estar fundamentadas nas características das populações mais vulneráveis de tal forma a proporcionar os meios adequados para permitir sua integração e melhorar sua autonomia, que se veem prejudicadas por propostas de design dirigidas a usuários videntes, priorizando o sentido da visão em relação aos demais sentidos. Para um design inclusivo deve ser estabelecida a igualdade de direitos e oportunidades que emanam de necessidades comuns entre todas as pessoas, independentemente de suas habilidades e capacidades. No entanto, neste processo de idealização do design, essa "universalização" deveria ser desconsiderada, ou seja, não se deve tratar como igual algo que não é igual, posição esta que se fundamenta na compreensão da diversidade humana a partir das formas de interação espaciais e com os objetos, permitindo chegar a propostas que incluam as características, limites e capacidades de um maior número de pessoas.

Assim, para este estudo considera-se que existem qualidades espaciais e qualidades dos objetos, ambas condicionando os atos humanos. Uma das vantagens que o ser humano possui reside na sua capacidade de adaptação ao ambiente. $\mathrm{Na}$ maioria das vezes é necessário, principalmente, um domínio visual para a realização de procedimentos do ato de cozinhar e isso coloca o deficiente visual em desvantagem em relação a pessoas com visão normal.

\footnotetext{
${ }^{1}$ Preparação de alimentos onde há uma forte influência cultural.
} 
O principal objetivo desta pesquisa é a determinação de parâmetros de caráter inclusivo para o design de produtos e espaços voltados ao ato de cozinhar, que sejam embasados na própria experiência de quem não enxerga. A abordagem da pesquisa qualitativa permite compreender em profundidade as necessidades de design presentes no ato de cozinhar de pessoas deficientes visuais e os modos de interação dessas pessoas com seus espaços e utensílios. Posteriormente foram realizadas análises e interpretação dos dados para concluir quais características devem ser consideradas par a configuração de espaços e objetos normalmente utilizados durante o ato de cozinhar para este público. O principal pressuposto é que a inclusão desses parâmetros de projeto propicie e facilite o ato de cozinhar para pessoas com deficiência visual, tornando-o mais seguro.

\section{UMA VISÃO GLOBAL DO ESTUDO}

A cegueira se estabelece como uma condição humana imutável e traz consigo algumas limitações e incapacidades. Pode-se dizer que esta incapacidade encontra uma conexão com a atividade de cozinhar a partir do momento em que surge a necessidade da pessoa se alimentar, de modo que possa satisfazer suas necessidades básicas. Assim como a cegueira ou qualquer tipo de incapacidade, cozinhar também possui um caráter complexo devido aos procedimentos, uso de objetos e utensílios em um entorno definido e que, ao mesmo tempo, é influenciado pela cultura de cada povo. Considerando a complexidade destes tópicos, o primeiro passo foi estabelecer um processo de decomposição do problema em suas partes mais simples a partir do terceiro princípio de simplificação denominado de Morin (2004, p.4), que estabelece que é necessário reduzir um sistema em suas partes mais simples e elementares para poder compreendê-lo. Assim, as pessoas deficientes visuais e o ato de cozinhar são aqui entendidos como um sistema no qual a informação do entorno chega ao deficiente por seus sentidos remanescentes e é levada ao cérebro a partir de terminações nervosas, o que se costuma chamar de percepção. Esta pesquisa observou e analisou estas percepções e suas manifestações externalizadas, que se traduziram em procedimentos no contato com os objetos e seu entorno.

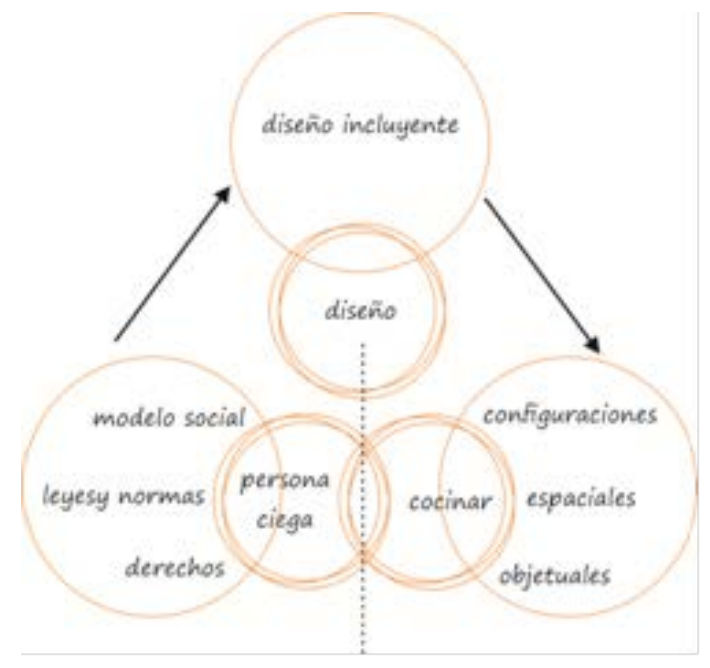

Figura 1 - Elementos do pensamento complexo.

Fonte: Elaborado por Iris Marcela López Rico, com base na pesquisa realizada. 
Do mesmo modo, é possível reduzir a atividade de cozinhar em suas partes mais simples se considerarmos que é formada por uma série de procedimentos nos quais se apresentam o uso de objetos e utensílios dentro de um entorno e que este conjunto entre objetos, utensílios e entorno é responsável por fazer com que o ato de cozinhar aconteça. Definida a inteligência como uma aptidão estratégica que permite tratar e resolver diferentes problemas em situações de complexidade (Morin, 2003, p.43), as adequações e soluções originárias de uma deficiência visual em procedimentos nos quais se detecta complexidade se colocam como elementos-chave, comparáveis com a realidade adversa da carência visual e representa um ponto de partida para propostas inclusivas focadas em elementos do espaço, do entorno e dos objetos mais comumente utilizados por esse público.

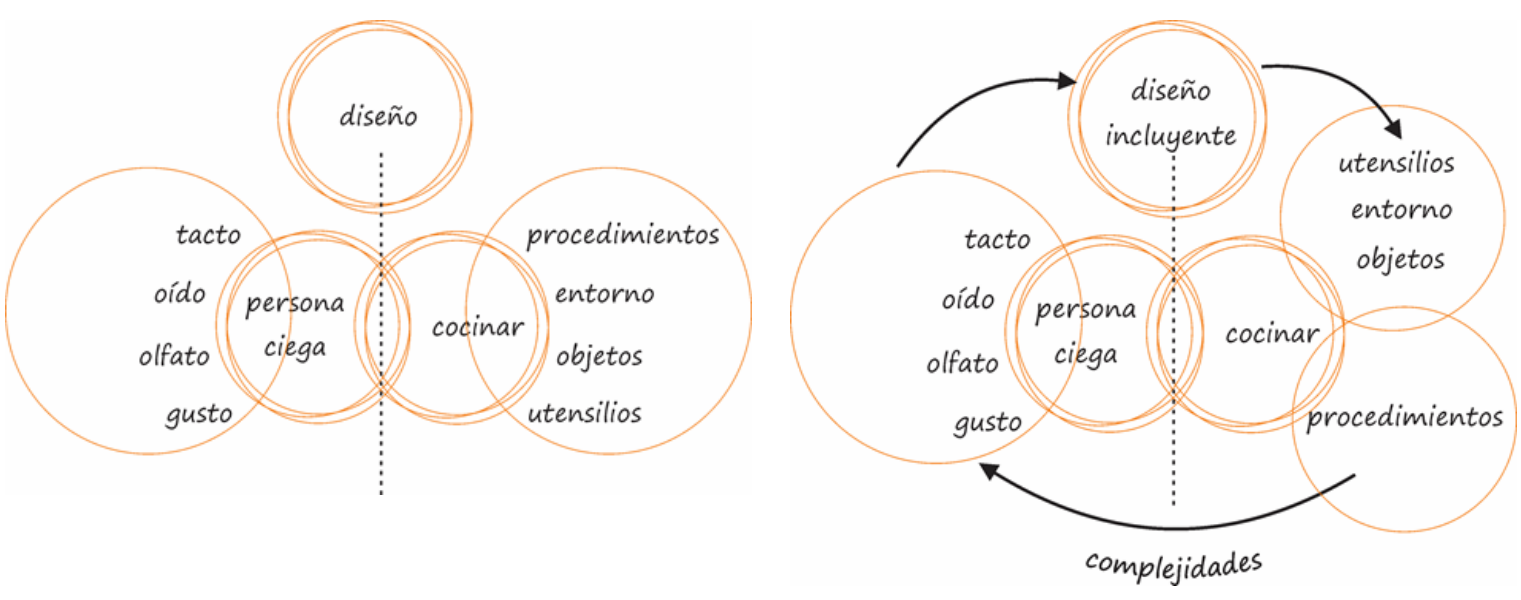

Figura 2 (esq.) - Elementos reduzidos em partes simples

Figura 3 (dir.) - Estratégia

Fonte: Elaborado por Iris Marcela López Rico, com base na pesquisa realizada.

\subsection{0 estudo}

Desde o início, a abordagem para esta investigação indicou uma necessidade de aproximação de pessoas com deficiência visual no momento em que cozinhassem. Desse modo, as primeiras aproximações permitiram conhecer o Como: como é feita a atividade de cozinhar por uma pessoa que não pode ver. Com o objetivo de delimitar de modo mais concreto o objeto de estudo, buscou-se realizar a análise exclusivamente com pessoas com cegueira congênita, ou seja, aquelas que já nasceram cegas. Contudo, a dificuldade de se encontrar participantes com este perfil para participar desta pesquisa fez necessária uma reformulação, estabelecendo-se a participação de pessoas com deficiência visual a não menos do que cinco anos, que cozinham regularmente. Por outro lado, a pesquisa se deu em espaços domésticos com os quais as pessoas já estavam habituadas a exercer a atividade. É importante mencionar que a partir dos tipos de deficiência visual, congênita ou tardia, ou seja, pessoas que nascem cegas ou aquelas que adquirem a deficiência visual em algum momento de sua vida, há diferentes formas de construção de imagens mentais que representam o meio pelo qual eles realizam suas atividades diárias. Uma pessoa com cegueira tardia fará uso de informações registradas em sua memória do tempo que gozava de visão e esta se soma a sua experiência como pessoa que, no tempo presente, carece do sentido da visão, enquanto uma pessoa com cegueira congênita 
fará uso de sua capacidade imaginativa, que é alimentada por informações obtidas por meio de seus outros sentidos, que lhe permitirão atuar sobre o entorno.

As pessoas foram filmadas em seu ambiente conhecido enquanto cozinhavam e conjuntamente estas eram questionadas, em alguns casos, a partir de um roteiro de entrevistas, em outros casos apenas perguntando-se o porquê de cada atividade realizada, de modo que se pudesse obter o maior número de dados possível em cada entrevista. As perguntas sobre o ato de cozinhar focaram principalmente em perceber aspectos relevantes sobre a experiência da pessoa com a atividade, sua complexidade, adaptações e formas de utilização dos outros sentidos. As entrevistas e filmagens foram realizadas em três etapas, sendo que na primeira foram entrevistadas três pessoas na cidade de Morelia (MX), na segunda foi entrevistada uma pessoa na cidade do México e a terceira uma pessoa em Campo Largo, no estado do Paraná (BR). Cabe ressaltar que houve a oportunidade de contar com a participação de um chef $^{2}$ de cozinha com deficiência visual, em um contexto industrial, o que fez com que novamente fossem alteradas as unidades de análise. Assim, a realização de uma análise com o chef possibilitou obter mais informações sobre procedimentos e formas de interação. Cronologicamente, apresentam-se abaixo os participantes do estudo:

1. Pessoa com cegueira tardia, 34 anos, perdeu a visão aos 29 anos devido a uma retinopatia diabética. Atualmente faz curso técnico de computação. Proveniente de Morelia, Michoacán, México.

2. Pessoa com cegueira tardia, 50 anos, perdeu a visão aos 45 anos. Os sintomas começaram com 37 anos devido a glaucoma. Proveniente de Morelia, Michoacán, México.

3. Pessoa com cegueira tardia, 43 anos, perdeu a visão de um dos olhos com 9 anos e do outro aos 12 devido a causas genéticas hereditárias. Proveniente de Morelia, Michoacán, México.

4. Pessoa com cegueira tardia, 31 anos, perdeu a visão aos 26 anos devido a uma diabete adquirida aos 15 anos e hipertensão, que se manifestou aos 21 anos. Estudou Design Gráfico quando ainda enxergava e atualmente é chef de cozinha formado e trabalha nesta profissão. Proveniente da Ciudad de México.

5. Pessoa com cegueira tardia, 45 anos, perdeu a visão aos 20 anos devido a um glaucoma de nascimento e baixa visão. Estuda carreira técnica em cerâmica. Proveniente de Campo Largo, Estado de Paraná, Brasil.

Uma questão importante de se mencionar: a fixação das handycams em tripés e locais fixos não se mostrou adequado pois os espaços encontrados eram pequenos e a atividade de cozinhar é dinâmica e pressupõe deslocamentos constantes. Desse modo, optou-se por seguir os participantes com a Câmera na mão, com o objetivo de capturar imagens e efetuar aproximações durante todo o processo enquanto era realizada a entrevista. Isso também permitiu que a pessoa que estava sendo filmada pudesse ter consciência da localização de quem a estava filmando. As análises foram divididas em duas partes: informações obtidas nas entrevistas e análise das imagens filmadas. Estas últimas foram interpretadas pelo método conhecido como AEIOU, no

2 Pessoa que tem maior hierarquia em um espaço gastronômico devido a seus conhecimentos na área, o que o diferencia de um cozinheiro, que é aquele que cozinha por ofício ou profissão. 
qual a letra A corresponde ao tipo de ação realizada; E corresponde ao entorno ou espaço no qual são executadas as ações; I corresponde à forma de interação com a ação; O corresponde aos objetos e artefatos ou utensílios empregados para realizar a ação; U corresponde à descrição do usuário. Um dos principais motes desta pesquisa é a forma de percepção não visual. Por isso, foi necessário anexar quatro elementos de análise correspondentes a cada um dos sentidos, ou seja, definir o modo com o qual era utilizado o tato, olfato, paladar ou audição em cada uma das atividades. Ao final foram incluídas mais duas categorias, correspondentes às complexidades observadas bem como às formas de execução de cada atividade a partir da ausência da visão. Desse modo, a tabela de análise ficou estabelecida conforme apresentada abaixo:

Quadro 1 - Quadro de análise do método AEIOU.

Fonte: Elaborado por Iris Marcela López Rico, com base na pesquisa realizada.

\begin{tabular}{|c|c|c|c|c|c|c|c|c|c|c|c|}
\hline мо. & acciom & ERTORROUЕsPACIO & interaccion & 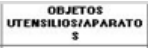 & UsurRio & $\begin{array}{c}\text { TAcro Activo } \\
\text { WAPTico }\end{array}$ & otrato & custo & oío & prostemA & ияеивzos \\
\hline \multirow{3}{*}{1} & & & & & encoon & $\checkmark$ & \multirow{3}{*}{$x$} & \multirow{3}{*}{$x$} & \multirow{3}{*}{$x$} & & \multirow{3}{*}{ 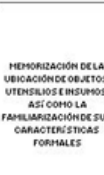 } \\
\hline & 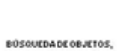 & & 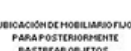 & 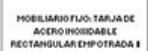 & & 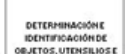 & & & & & \\
\hline & & & suremoncats & 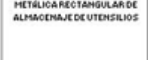 & 急 & 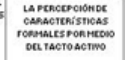 & & & & & \\
\hline
\end{tabular}

\section{RESULTADOS OBTIDOS}

As análises a seguir consideraram os seguintes autores para sua elaboração: Bonsiepe \& Yamada (1982), Bonsiepe (2013), Coleman et al.(2007), Martínez de la Peña (2007/ 2011), Merleau-Ponty (1993) e Norman (1990). Os principais conceitos sobre processos de design, perceptivos, de apropriação foram considerados para elaborar os itens de análise listados abaixo.

De acordo com as informações obtidas nas entrevistas e comparando estas com as informações obtidas nas filmagens, pode-se dizer que:

Em se tratando de habilidades e autonomia:

a. A habilidade e destreza da pessoa se relaciona com o tempo de aquisição da deficiência, bem como com o seu gosto pelo ato de cozinhar;

b. Ter aprendido a cozinhar antes de perder a visão se reflete em mais facilidade para a pessoa realizar as atividades;

c. A atitude dos indivíduos que compartilham as áreas de trabalho com pessoas com deficiência visual tem grande impacto na autonomia destas pessoas.

Em se tratando dos sentidos empregados para realizar as tarefas:

a. O tato e o olfato se colocam em primeiro lugar, seguidos pela audição e, por último, pelo paladar;

d. O cálculo de cocções é determinado, na maior parte das vezes, pelo tato ativo e passivo, audição e olfato;

e. O cálculo de quantidades sólidas é determinado a partir do tato ativo;

f. O cálculo de quantidades líquidas é determinado pelo tato ativo e passivo, assim como também pela audição;

g. O olfato e a audição alertam a pessoa; 
h. A percepção e diferenciação das formas e consistências é determinada a partir do tato ativo;

i. A diferenciação de produtos com o mesmo tipo de embalagem ou formato é determinada a partir do olfato e do som que produz quando agitado;

j. O estado de funcionamento de artefatos é determinado pela audição;

Complexidades:

a. Na diferenciação de funções dos artefatos em superfícies planas;

b. Na pesagem de quantidades exatas;

c. Para conferir os alimentos;

d. Para virar as omeletes;

e. Para determinar o tempo de cocção de alguns alimentos;

f. Para picar os alimentos em pedaços finos;

Acidentes e incidentes:

a. Queimaduras e cortes são minimizados quando fazem uso constante da memória;

b. Algumas situações de cortes com facas se devem a certas colocações e disposição dos mesmos;

c. Confusão entre produtos por estarem em embalagens similares entre si e também terem consistências parecidas;

Ajudas recebidas:

a. Para realizar a colocação das mesas;

b. Para ligar alguns utensílios;

c. Para ajustar a chama do fogão e do forno;

d. Para garantir o acendimento.

De acordo com as análises realizadas a partir das filmagens das quatro pessoas no Méxcio em 2014 e uma no Brasil em 2015, foram identificados padrões de comportamento compartilhados pelas cinco pessoas estudadas, permitindo uma categorização e ordenamento de atividades de acordo com a ordem na qual foram executadas. Cabe mencionar que, devido à grande variação de pratos realizados, em um primeiro momento foi complicado estabelecer uma lista que representasse todos os processos feitos pelas cinco pessoas. Apesar disso, ao realizar uma análise mais detalhada foi possível desenvolver um processo de categorização com o reconhecimento das atividades que derivam de uma mesma linha. Desse modo, os procedimentos identificados foram os seguintes:

1. Buscar utensílios e insumos;

2. Identificar insumos;

3. Selecionar insumos;

4. Lavar e desinfetar os alimentos;

5. Colocar objetos, utensílios e alimentos em superfícies de trabalho;

6. Descascar os alimentos;

7. Cortar os alimentos;

8. Retirada das cascas e resíduos; 
9. Esvaziar;

10. Condimentar;

11. Usar os artefatos e utensílios;

12. Cocção dos alimentos;

13. Fritura;

14. Verificação dos alimentos quentes;

15. Limpeza de objetos, utensílios e superfícies;

16. Guardar objetos e utensílios.

Posteriormente e enfatizando que a lista acima corresponde às atividades a partir do método AEIOU, um dos elementos fundamentais para se chegar aos objetivos estabelecidos nesta pesquisa foi relacionar os sentidos que eram empregados em cada atividade, assim como os objetos e artefatos. Desse modo, apresenta-se abaixo uma tabela com essas categorias:

Quadro 2- Análise de categorias, sentidos empregados e objetos utilizados

\begin{tabular}{|c|c|c|}
\hline CATEGORIA & SENTIDO EMPREGADO & OBJETO QUE INTERVIU \\
\hline $\begin{array}{l}\text { Buscar utensílios e } \\
\text { insumos; }\end{array}$ & Tato ativo e passivo & $\begin{array}{l}\text { Refrigerador, superfícies para } \\
\text { armazenagem }\end{array}$ \\
\hline Identificar insumos; & $\begin{array}{l}\text { Tato ativo } 50 \% \text {, olfato } 25 \% \text {, } \\
\text { Audição } 25 \%\end{array}$ & $\begin{array}{l}\text { Refrigerador, superfícies para } \\
\text { armazenagem }\end{array}$ \\
\hline Selecionar insumos; & Tato ativo & $\begin{array}{l}\text { Refrigerador, superfícies para } \\
\text { armazenagem }\end{array}$ \\
\hline $\begin{array}{l}\text { Lavar e desinfetar os } \\
\text { alimentos; }\end{array}$ & Tato ativo e passivo & Vasilha, produtos para desinfetar \\
\hline $\begin{array}{l}\text { Colocar objetos, } \\
\text { utensílios e alimentos em } \\
\text { superfícies de trabalho; }\end{array}$ & Tato ativo e passivo & Superfícies \\
\hline Descascar os alimentos; & Tato ativo & $\begin{array}{l}\text { Faca, superfície para corte, superfície } \\
\text { fixa }\end{array}$ \\
\hline Cortar os alimentos; & Tato ativo & $\begin{array}{l}\text { Faca, superfície para corte, superfície } \\
\text { fixa, recipiente de armazenagem }\end{array}$ \\
\hline $\begin{array}{l}\text { Retirada das cascas e } \\
\text { resíduos; }\end{array}$ & $\begin{array}{l}\text { Tato ativo } 50 \% \text {, } \\
\text { Audição } 50 \%\end{array}$ & Lixo, superfície \\
\hline Esvaziar; & $\begin{array}{l}\text { Tato ativo } 60 \% \text {, } \\
\text { Audição } 40 \%\end{array}$ & $\begin{array}{l}\text { Objetos contentores de sólidos e } \\
\text { líquidos }\end{array}$ \\
\hline Condimentar; & Tato ativo & Recipientes, superfícies, refrigerador \\
\hline $\begin{array}{l}\text { Usar os artefatos e } \\
\text { utensílios; }\end{array}$ & Tato ativo, audição & Liquidificador \\
\hline Coç̧ão dos alimentos; & $\begin{array}{l}\text { Tato ativo } 50 \% \text {, } \\
\text { Olfato } 40 \% \text {, audição } 10 \%\end{array}$ & Fogão, panelas, utensílios \\
\hline Fritura; & $\begin{array}{l}\text { Tato ativo } 50 \% \text {, } \\
\text { Olfato } 40 \% \text {, audição } 10 \%\end{array}$ & Fogão, panelas, utensílios \\
\hline $\begin{array}{l}\text { Verificação dos alimentos } \\
\text { quentes; }\end{array}$ & $\begin{array}{l}\text { Olfato } 50 \% \text {, tato } 30 \% \text {, } \\
\text { Paladar } 15 \% \text {, audição } 5 \%\end{array}$ & Fogão, panelas, utensílios \\
\hline $\begin{array}{l}\text { Limpeza de objetos, } \\
\text { utensílios e superfícies; }\end{array}$ & Tato ativo & Vasilhas, superfícies \\
\hline $\begin{array}{l}\text { Guardar objetos e } \\
\text { utensílios. }\end{array}$ & Tato ativo & $\begin{array}{l}\text { Refrigerador, superfícies de } \\
\text { armazenagem. }\end{array}$ \\
\hline
\end{tabular}

Fonte: Elaborado por Iris Marcela López Rico, com base na pesquisa realizada. 
Ampliando a explicação sobre as análises realizadas, pode-se perceber que o tato os ajuda na identificação e seleção de objetos, utensílios e insumos, de acordo com as características formais percebidas. Também lhes permite o cálculo de quantidades líquidas e sólidas, sendo que neste último caso é onde termina o processo de "fechamento" com as mãos. Por outro lado, o tocar rápido nas chamas bem como em alimentos durante o cozimento, no caso das três pessoas entrevistadas no México em um espaço doméstico, se mostrou indispensável para assegurar-se do correto acendimento do fogão, bem como do ponto de cocção, a partir da percepção de diferentes consistências.

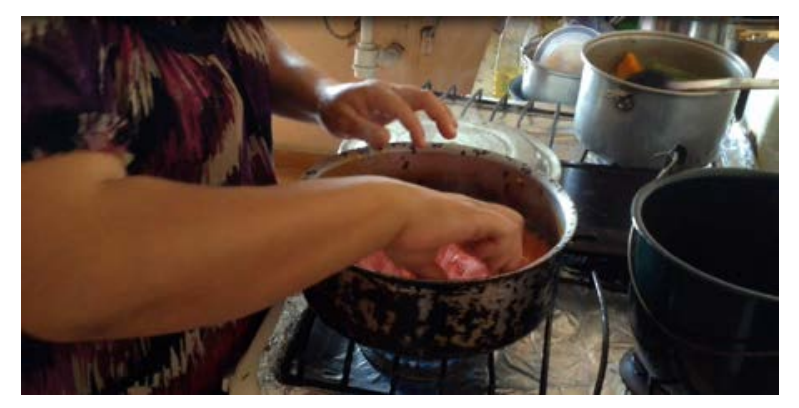

Figura 4 - usuária com deficiência visual verificando a cocção do alimento com as mãos. Fonte: Elaborado por Iris Marcela López Rico, com base na pesquisa realizada.

No caso da pessoa deficiente visual entrevistada no Brasil, a percepção do calor foi feita por meio da palma da mão, sem necessidade de tocar rapidamente e diretamente sobre a chama, sendo que para estes dois o som gerado pelo alimento colocados nas panelas em contato com a fonte de calor era o que os permitia determinar o estado de cocção. Em todos os casos a localização de vasilhas e recipientes por meio do tato se fez presente para posteriormente se misturarem sólidos e líquidos. O uso do olfato ajuda a determinar o estado de cocção dos alimentos, bem como a diferença entre os insumos que possuem características formais similares ao tato. Por meio da audição é possível calcular quantidades líquidas, a partir do som gerado pelo produto ao ser despejado de um recipiente a outro. 0 mesmo sentido determina o estado de fritura ou cocção, dependendo do tipo de alimento que está sendo submetido ao processo pois a colocação dos alimentos juntamente com condimentos e outros produtos produzem um som que difere de acordo com a etapa de fritura ou cocção na qual se encontram. É possível diferenciar produtos com embalagens similares por meio do som gerado no momento em que são agitadas. Por fim, o paladar também ajuda a determinar o estado de cocção dos alimentos. Como já foi dito anteriormente, uma série de atividades só são possíveis por meio de objetos ou utensílios, onde a interação com os mesmos é efetuada a partir do uso de determinados sentidos, o que nos indica caminhos para estabelecer propostas e parâmetros de design em elementos espaciais e dos objetos com enfoque inclusivo. 


\section{DISCUSSÃO}

As primeiras conclusões apontam que a memorização e a localização dos artefatos, utensílios e insumos bem como suas características formais são itens essenciais para poder cozinhar com maior eficiência. Por outro lado, a organização dos insumos realizada pelos usuários nos locais de armazenamento permitiu sua rápida localização.

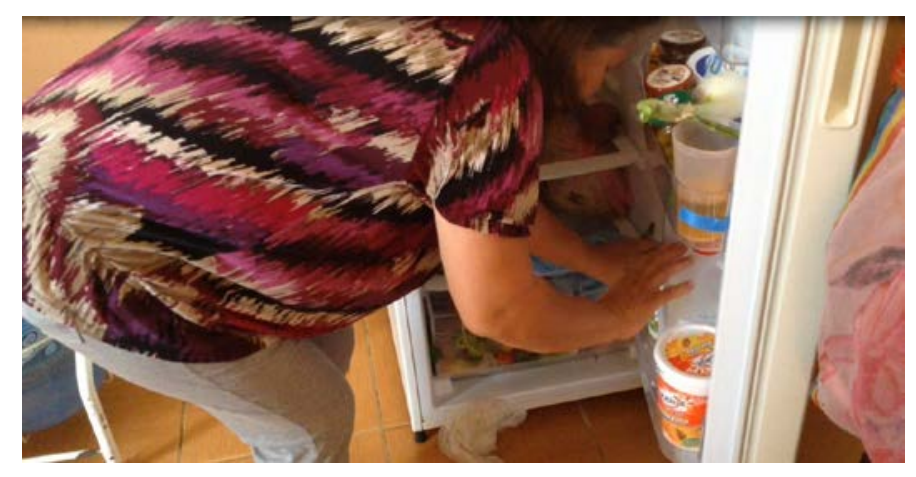

Figura 5 : usuária deficiente visual localizando os objetos e alimentos na geladeira. Fonte: Elaborado por Iris Marcela López Rico, com base na pesquisa realizada.

No que diz respeito ao uso dos sentidos, o tato tem predomínio sobre os demais sentidos, a partir da sua maior presença nos quadros de análise, que mostra sua preponderância na maioria dos procedimentos observados. Além disso, sua importância recai sobre o fato de permitir a construção de um mapa mental da zona da cozinha a partir do apalpar de superfícies. Da mesma forma, os processos identificados são realizados de forma minuciosa, com exceção do chef, que tem expertise profissional.

Considerando os elementos mais específicos e que podem ser catalogados dentro do campo do design industrial, pode-se perceber que os fogões têm uma forte influência tecnológica que geraram desenhos mais limpos e planos, incluindo os elementos de interface com os usuários. Isso ocasionou uma dificuldade de manuseio por parte dos deficientes visuais, uma vez que apenas pela visão é possível identificar as diferenças. No mesmo sentido, os botões e puxadores, dependendo da marca, são acionados de maneiras diferentes apesar de serem todos iguais, ou seja, tem a mesma forma. Isso inclui o acendedor do forno, que antigamente era de tamanho diferente, fazendo com que fosse possível notar a diferença pelo tato. Também podem ser mencionados outros elementos que são colocados sobre os fogões, como por exemplo os queimadores, cujo desenho, em especial o espaço de separação, pode ocasionar que as panelas e frigideiras de menor dimensão virem.

Continuando com as observações de características específicas, pode-se observar que alguns fogões emitem um som peculiar que permite conhecer quando uma grade está presa e funcionando corretamente, mas em alguns casos isso se torna em um som quase imperceptível, de modo que se estiver aberta e deixando escapar o gás, também será imperceptível ao deficiente visual. Por outro lado, uma das situações mais comuns entre diversas pessoas é que, mesmo com experiência no uso do fogão, em muitas ocasiões erraram no acendimento, ligando uma boca que não era a que queriam acender. 


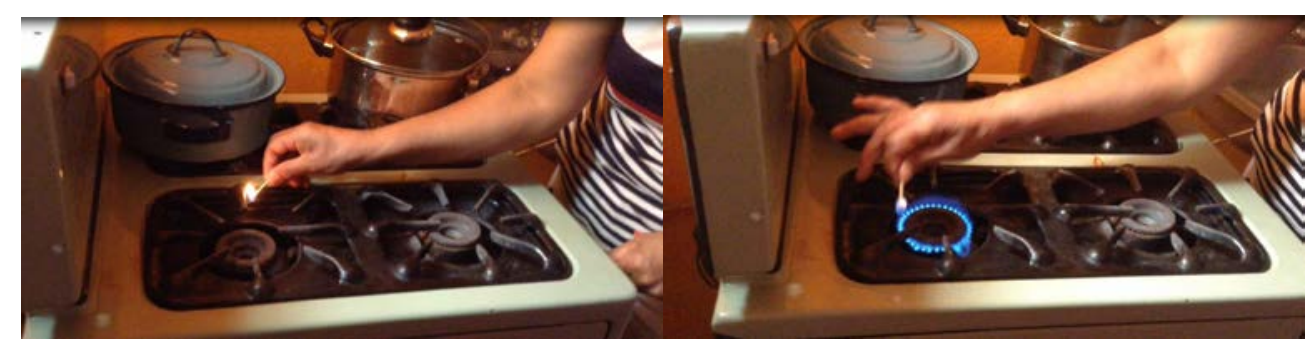

Figura 6 - Usuária com deficiência visual acendendo o fogão.

Fonte: Elaborado por Iris Marcela López Rico, com base na pesquisa realizada.

Na mesma categoria de artefatos pode-se encontrar outros cuja interface resulta complexa para a maioria das pessoas, sem contar com nenhuma deficiência. Entre os mais comuns está o forno de micro-ondas, que se caracteriza por ter um grande número de funções que são muito pouco usadas, a maior parte com um design plano. Alguns deficientes visuais encontraram uma solução ao colocar relevos nos botões, enquanto outros memorizaram onde se liga e desliga.

\section{CONSIDERAÇÕES FINAIS}

Apesar de ter apenas uma pessoa entrevistada no Brasil, ao comparar as pessoas e atividades dos dois países, pode-se observar que existem aspectos a considerar e que influenciam de maneira direta na forma pela qual a pessoa se apropria de seu espaço e atua no mesmo. No caso do Brasil, existe uma maior independência outorgada à pessoa com deficiência visual, o que se reflete em sua autonomia no momento de cozinhar. Por outro lado, no caso do México, existe uma atitude para com pessoas com deficiência visual que as rotulam, colocando-as na sociedade como alguém incapaz de realizar atividades diárias, como por exemplo cozinhar. Observaram-se habilidades a partir de duas perspectivas: por um lado, a execução de atividades como meio pelo qual alimentam a outras pessoas e a si mesmos, tornando-se o cozinhar uma atividade fundamental e obrigatória, enquanto, por outro lado, o gosto por cozinhar se reflete nas habilidades mostradas por alguns participantes.

Em relação às questões do espaço, tanto no México quanto no Brasil a pessoa com deficiência visual modifica seu espaço de acordo com seus gostos e necessidades, dependendo de condições econômicas e limitações espaciais relacionadas especialmente com instalações de água, luz e gás. Em ambos os países se observou que a pessoa se adapta às condições de seu espaço, contudo exige mesmo assim uma organização dos utensílios e ferramentas, devendo solicitar às pessoas com quem compartilha o espaço para manter a cozinha na mesma organização para que o deficiente possa realizar as atividades contando com a memória, sentidos e cálculos de tempo. Alguns eletrodomésticos são essenciais para permitir o ato de cozinhar, como por exemplo o fogão e o refrigerador, e em ordem de importância pode-se citar o micro-ondas e o liquidificador, os quais, independentemente das marcas mexicanas ou brasileiras, percebe-se uma carência de informação relacionada ao seu funcionamento que sejam perceptíveis de uma forma distinta que não a visual. Isso provoca uma dependência de terceiros na hora de utilizar esses artefatos, adaptações para seu uso, como a colocação de etiquetas com relevos ou, em casos extremos, à limitação do uso do eletrodoméstico devido à falta de segurança no manuseio do produto. Na mesma 
direção, aponta-se que um maior número de funções no produto complica ainda mais o seu uso para um deficiente visual.

Em relação aos utensílios, percebeu-se que seu uso depende do gosto de cada pessoa, assim como do procedimento que deseja realizar. No caso das facas existem preferencias pelo tipo de lâmina, visto que algumas pessoas se sentem mais seguras ao cortar com determinado tipo.

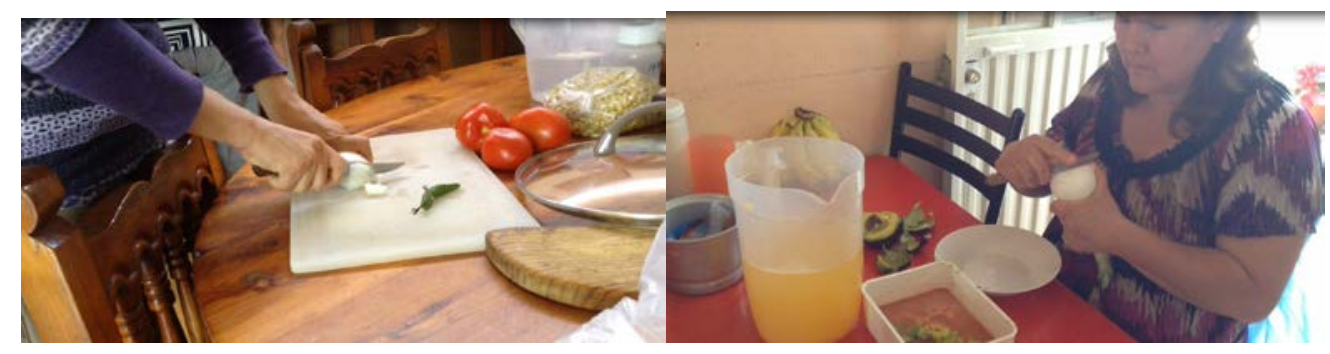

Figura 7 - Usuárias com deficiência visual utilizando diferentes tipos de faca.

Fonte: Elaborado por Iris Marcela López Rico, com base na pesquisa realizada.

Mencionando aspectos próprios de uma cultura e com relação aos procedimentos realizados no ato de cozinhar, encontram-se aqueles que são indiretos, como por exemplo servir os alimentos. No caso do Brasil, esta ação é normalmente realizada pela pessoa que cozinha, deslocando-se da boca do fogão para servir cada prato às pessoas na mesa, com um trajeto do fogão à mesa. A maior parte dos deficientes visuais evitam esta ação, por questões de segurança e medo de queimaduras. Já no México, este procedimento não existe, pois, os alimentos cozidos são levados à mesa para que as pessoas se sirvam.

Assim, a importância da atividade do designer está em colocar maior ênfase nas necessidades e formas de interação para atender ao seu usuário, o que se traduz em qualidades espaciais e formais dos objetos que permitem às pessoas executarem determinadas atividades sem complicações e de forma segura, principalmente os deficientes visuais. Além disso, considerar as condições físicas e aspectos culturais se mostrou relevante para a interpretação das formas de interação para se propor um design inclusivo. Nesse sentido, para finalizar, cabe reforçar a importância de pesquisas locais que produzam dados primários, uma vez que a hegemonia de dados americanos e europeus para aplicação em projetos de design podem resultar em produtos ineficientes para os usuários locais, no caso dos países latino-americanos.

\section{REFERÊNCIAS}

BONSIEPE, G. Design, Cultura e Sociedade. São Paulo: Blucher, 2013.

BONSIEPE, G., YAMADA, T. Desenho industrial para pessoas deficientes. Brasília: CNPq - Coordenação editorial, 1982.

COLEMAN et al. Design for inclusivity. A practical guide to accesible, innovative and user-centered design. England: Gower, 2007.

MARTÍNEZ DE LA PEÑA, G. El diseño táctil como una alternativa de acceso a la comunicación. SIGRADI MX. 2007, México, Anais... PP. 243-247. 
El diseño háptico, un paradigma diferente. La percepción y su importancia en la generación de un diseño háptico para personas con discapacidad visual. México: EAE, 2011.

MERLEAU-PONTY, M. Fenomenología de la percepción. Tradução de Jem Cabanes. Barcelona: Planeta-Agostini, 1993.

MORIN, E. La humanidad de la humanidad. La ideantidad humana. Tradução de Ana Sánchez. $1^{\circ}$ edição. Madrid: Cátedra Teorema, 2003. 02, 1-14, 2004.

La epistemología de la complejidad. Gazeta de Antropología, 20, artículo NORMAN, D. La psicología de los objetos cotidianos. Madrid: NEREA, 1990. 